Original Research Paper

\title{
Pressure Ulcer Prevention: Optimizing a Temporally Redistributing Support Interface
}

\author{
${ }^{1}$ Joshua M. Peterson, ${ }^{1}$ Colleen P. Healey, \\ ${ }^{2}$ G. Jacobus Visser, ${ }^{2}$ Cameron Crombie and ${ }^{1}$ Eric H. Ledet \\ ${ }^{I}$ Department of Biomedical Engineering, Rensselaer Polytechnic Institute, Troy, NY, USA \\ ${ }^{2}$ Department of Mechanical and Mechatronic Engineering, \\ Stellenbosch University, Stellenbosch, Republic of South Africa
}

\author{
Article history \\ Received: 01-12-2016 \\ Revised: 02-12-2016 \\ Accepted: 21-12-2016 \\ Corresponding Author: \\ Eric H. Ledet \\ Department of Biomedical \\ Engineering, Rensselaer \\ Polytechnic Institute, Troy, \\ NY, USA \\ Email: ledete@rpi.edu
}

\begin{abstract}
One of the most common complications from long-term wheelchair use or bed rest is pressure ulcers. Pressure ulcers have significant morbidity and are associated with high mortality. Prolonged sitting can cause high pressures in the skin and subcutaneous tissue which can lead to local ischemia and breakdown of skin. Rapid relief of pressure prevents ulcer formation. One prevention strategy is to change the temporal distribution of pressure at the interface between user and surface so that no one area is subjected to high pressures for long periods of time. While there are several dynamic interfaces in use currently, there is no definitive evidence of enhanced pressure ulcer prevention with their use. The purpose of this research was to parametrically evaluate interface array sizes, shapes and patterns for dynamic support surfaces to optimize pressure redistribution to prevent pressure ulcers. Finite element analyses, anatomical phantom deep tissue pressure measurements and interface pressure mapping were used to test various support geometries and sizes and different array spacing and patterns. Results indicate that modulating pressure in an array of supports that are equally spaced is not effective. Only interrupted pattern arrays resulted in sufficient pressure reduction. These data suggest that dynamic surface supports can be optimized based on the geometry and size of the individual supports and the pattern of the array to further reduce the likelihood of pressure ulcer formation.
\end{abstract}

Keywords: Pressure Ulcer, Pressure Sore, Wheelchair, Seating

\section{Introduction}

According to the World Health Organization, there are more than 70 million wheelchair users worldwide. For users with impaired ability to reposition themselves, one of the most common complications from long-term wheelchair use or bed rest is pressure ulcers (Coleman et al., 2013). In 2008, the World Health Organization identified pressure ulcers as one of the top 20 patient safety issues worldwide (WHO, 2008) and in that same year, pressure ulcers were recognized as the most common medical error in the United States (Van Den Bos et al., 2011).

The prevalence of pressure ulcers is more than 3 million in the US and estimated to be more than 7.4 million worldwide (Sen et al., 2009) with higher prevalence in developing countries (WHO, 2008). Among inpatients, pressure ulcer incidence is as high as $38 \%$ depending on nature of injury while in long term care settings, the incidence is reported at 24\% (Xakellis, 1992; Cuddigan et al., 2001). Up to $66 \%$ of paraplegics will develop pressure ulcers (Richardson and Meyer, 1981).

Pressure ulcers have significant morbidity and are associated with high mortality (Redelings et al., 2005; Khor et al., 2014). In underdeveloped healthcare systems, pressure sores are one of the leading cause of death among individuals with disabilities. Without proper treatment, pressure ulcers can lead to cellulitis, osteomyelitis, sepsis and death (WHO, 2008). Average length of hospital stay for treatment of pressure ulcers is 13 days (Sen et al., 2009) and healing can take up to several years (Stockton and Rithalia, 2007). More than 
$\$ 11$ billion is spent annually on pressure ulcer treatments in the US (Sen et al., 2009) and the cost of treatment for individual pressure ulcers averages from $\$ 8,730$ to $\$ 129,248$ depending on how advanced the ulcer is (Van Den Bos et al., 2011; Sen et al., 2009; Palfreyman and Stone, 2015; Lyder, 2003). Prevention is a more cost effective option (Sullivan and Schoelles, 2013).

The physiology of pressure ulcer formation is complex (Reuler and Cooney, 1981). Pressures ulcers are a local breakdown of skin and underlying tissue caused by unrelieved pressure (Brienza et al., 2001; Grey et al., 1974). One of the most significant contributing factors is ischemia from prolonged pressure which occludes vessels in the skin and subcutaneous tissues (Stekelenburg, 2005). Healthy capillary pressure is approximately $32 \mathrm{mmHg}$. Prolonged sitting can cause high pressures in the skin and subcutaneous tissue in areas where body weight is concentrated. If pressure from sitting obstructs capillary blood flow, ischemia results and pressure ulcers can develop within 2 to 6 hours (Lyder, 2003; Stekelenburg, 2005). If peak pressures exceed $60 \mathrm{mmHg}$, the incidence of pressure ulcers increases (Conine et al., 1993). Pressure ulcers are most common superficial to the sacrum, coccyx and ischial tuberosities (Cuddigan et al., 2001; Richardson and Meyer, 1981).

Prolonged high pressures also result in the accumulation of toxic metabolites which contribute to tissue necrosis even after reperfusion (Stekelenburg, 2005; Krouskop et al., 1978). Temperature, moisture, skin friction and shear forces also contribute to skin breakdown and pressure ulcer formation (Xakellis, 1992; Grey et al., 1974; Stekelenburg, 2005; Reichel, 1958). Pressure ulcers can also initiate in the deep tissues due to sustained mechanical loading of muscle (Stekelenburg, 2005).

There are two parameters that are significant in preventing pressure ulcer formation: Pressure magnitude and duration. Rapid relief of pressure, even at higher pressure magnitude $(70 \mathrm{mmHg})$ prevents ulcer formation (Kosiak, 1959). Tissues exposed to pressures up to $200 \mathrm{mmHg}$ for $1.5 \mathrm{~h}$ showed minimal pathologic changes (Dinsdale, 1974). When pressure of short duration is relieved, tissues demonstrate reactive hyperaemia, reflecting increased blood flow to the area (Grey et al., 1974). As shown in Fig. 1, the relationship between pressure magnitude, pressure duration and risk of pressure ulcer formation has been characterized. Individuals on long term bed rest who are repositioned at least every $2 \mathrm{~h}$ have a reduced incidence of pressure ulcer formation (Xakellis, 1992). Best practice for long term wheelchair users is to shift weight approximately every $15 \mathrm{~min}$ (Xakellis, 1992; Grey et al., 1974).

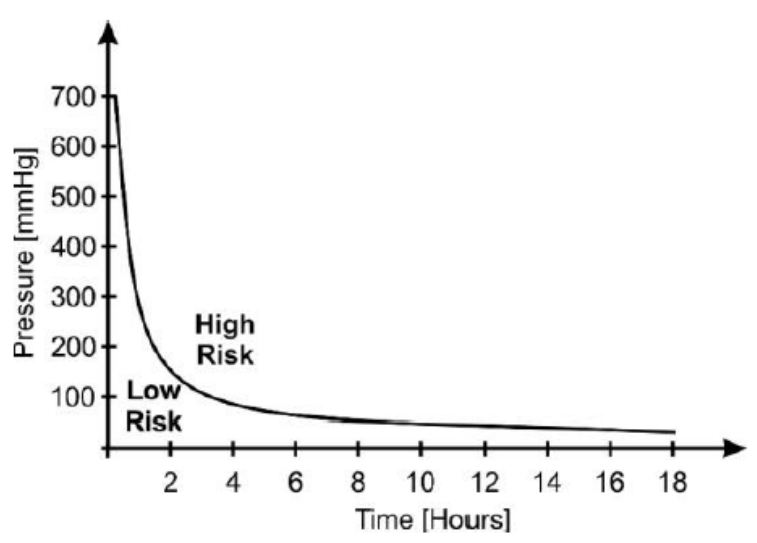

Fig. 1. The relationship between pressure magnitude, pressure duration and risk of pressure ulcer formation indicates that tissues are tolerant of high magnitude pressures if they are relieved quickly. Reproduced from the work of Stekelenburg (2005) and Sacks (1989)

Most current prevention strategies are based on reducing the magnitude of pressure everywhere at the interface between the user and the seat (Xakellis, 1992; Taylor, 2003). This strategy generally involves static cushions some of which are contoured or customized to the user. Static cushions are relatively inexpensive and easy to use and are commonly utilized in developing healthcare systems. However, static cushions do not always reduce pressure sufficiently near bony prominences (Stockton and Rithalia, 2007). They also become ineffective once they "bottom out", fatigue, or in the case of customized cushions, if the user's BMI changes (Stockton et al., 2009; Hollington et al., 2014). Gel and air filled cushions mold to the user to increase surface area and reduce contact pressure. However, these cushions can affect user balance, must be constantly maintained for correct function and will leak if punctured (Stockton et al., 2009; Stockton and Rithalia, 2009).

Alternative prevention strategies are based on changing the temporal distribution of pressure so that no one area is subjected to high pressures for long periods any length of time. The interface between the user and the surface is modulated temporally. However, all existing dynamic support surfaces are based on regular patterns of supports with no optimization of support array, size, shape, etc. While there are several dynamic interfaces in use currently, there is no definitive evidence of enhanced pressure ulcer prevention with their use (Reddy et al., 2006; McInnes et al., 2011; Qaseem et al., 2015). Furthermore, the support array sizes, shapes and patterns for dynamic support surfaces has not been optimized. The purpose of this research was to parametrically evaluate various support array sizes, shapes and patterns to determine their effectiveness at optimal pressure redistribution for a dynamic wheelchair interface for prevention of pressure ulcers. 


\section{Materials and Methods}

Finite Element Analyses (FEA), anatomical phantom deep tissue pressure measurements and interface pressure mapping were used to test for differences between various seating support interfaces to determine which combination of parameters (support geometry and size; array spacing and pattern) would result in maximum relief of pressure during dynamic modulation of the supports. The goal was to identify an interface support array that could be modulated so that at any time, half of the array is supporting the user while the other half allows reperfusion of tissues (pressure less than $32 \mathrm{mmHg}$ ). To be clinically viable, when the dynamic support array is modulated, the roles switch so no tissue experiences pressures in excess of $32 \mathrm{mmHg}$ continuously.

\section{Finite Element Analysis}

A previously validated finite element model from Oomens et al. (2003) was adapted to predict the effect of support geometries on superficial and deep tissue pressures. An image of an MRI scan of a seated buttocks from a 29 year old female from previously published work (Sopher et al., 2010) was imported into SolidWorks (Dassault Systèmes SolidWorks Corp.; Waltham, MA). The boundaries between bone, fat and muscle tissue on the cross sectional image were traced with splines to obtain a two dimensional model for finite element analysis as shown in Fig. 2.

The model geometry was imported into MARC Mentat (MSC Corp.; Newport Beach, CA) and meshed using quadrahedral elements. The fat and muscle tissues were modeled as materials with non-linear mechanical properties using an Ogden model which describes the mechanical behavior of highly elastic incompressible "rubberlike" solids (Ogden, 1972) using the strain energy function shown in Equation 1:

$W=\sum_{n=1}^{N} \frac{\mu_{n}}{\alpha_{n}}\left(\lambda_{1}^{\alpha_{n}}+\lambda_{2}^{\alpha_{n}}+\lambda_{3}^{\alpha_{n}}-3\right)$

The Ogden model represents material mechanical properties with $\lambda_{i}$ denoting principal strains while $\mu_{n}$ and $\alpha_{n}$ are material parameters determined from empirical testing. The constant $\mu$ is analogous to modulus, while $\mathrm{n}$ and $\alpha$ are used to describe the power of the strain energy density curve. Previously published finite element models of seated tissue pressures have assumed $N=1$ and the material parameters shown in Table 1 (Oomens et al., 2003).

In order to reduce computational load, we modeled the ischial tuberosities as rigid bodies due to their significantly higher stiffness than the surrounding tissues. The finite element model was utilized to evaluate the effect on tissue pressure within the buttocks when seated on a flat interface and when seated on a support array with hemispherical supports $15.75 \mathrm{~mm}$ in diameter spaced $17.5 \mathrm{~mm}$ between arc centers. The supports were modeled as rigid bodies with a coefficient of friction of $\mu_{f}=0.4$ with the buttocks. To simulate the stresses and strains due to sitting, a $14.6 \mathrm{~mm}$ downward displacement was applied to the ischial tuberosity (Sopher et al., 2010). From the model, we determined the minimum superficial tissue pressures between supports, maximum superficial tissue pressure and deep tissue pressure.

Table 1. Parameters of ogden model materials

\begin{tabular}{lll}
\hline Tissue type & Modulus $\mu(\mathrm{MPa})$ & Exponent $\alpha$ \\
\hline Fat & 0.010 & -5 \\
Muscle & 0.003 & -30 \\
\hline
\end{tabular}

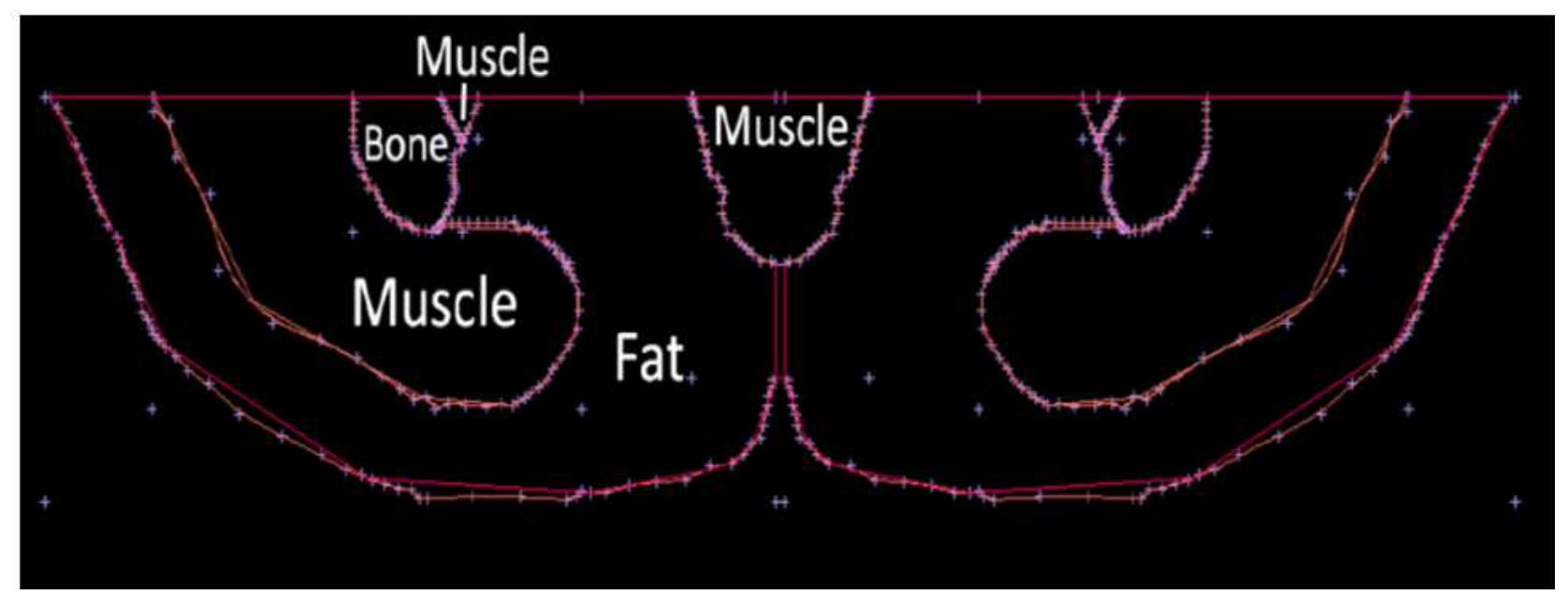

Fig. 2. The cross sectional model of the buttocks is comprised of discrete redions representing anatomical structures of bone, muscle and fat 


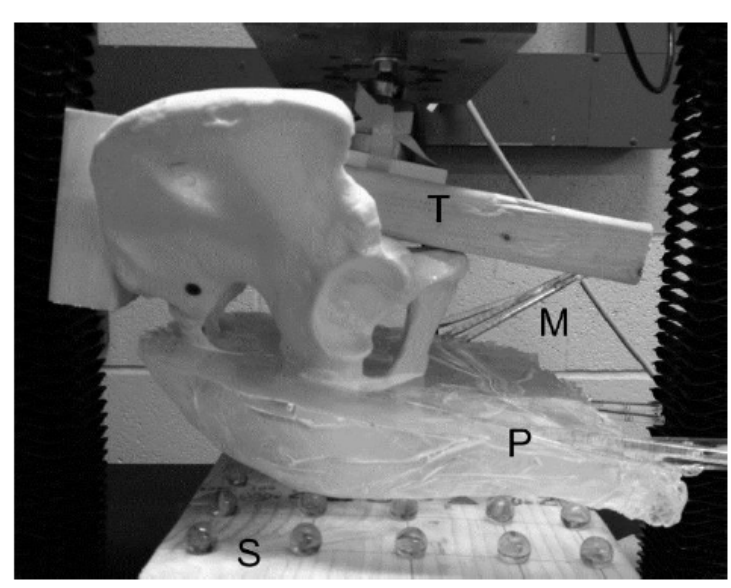

Fig. 3. An anatomical phantom $(\mathrm{P})$ was fabricated to measure the deep pressures adjacent to the ischial tuberosities and the sacrum using manometers $(\mathrm{M})$ for different support array configurations (S) while being loaded in a mechanical testing machines $(\mathrm{T})$

$\underline{\text { Table 2. Test interface support array sizes and spacings }}$

\begin{tabular}{llc}
\hline Support shape & $\begin{array}{l}\text { Support } \\
\text { diameter }(\mathrm{mm})\end{array}$ & $\begin{array}{l}\text { Support spacing } \\
\text { center to center }(\mathrm{mm})\end{array}$ \\
\hline Cylindrical & 22.0 & 7.8 \\
Cylindrical & 22.0 & 25.4 \\
Cylindrical & 26.0 & 7.8 \\
Cylindrical & 26.0 & 25.4 \\
Cylindrical & 34.0 & 7.8 \\
Cylindrical & 34.0 & 25.4 \\
Spherical & 16.2 & 6.4 \\
Spherical & 16.2 & 19.0 \\
Spherical & 16.2 & 25.4 \\
Spherical & 16.2 & 51.0 \\
\hline
\end{tabular}

\section{Anatomical Phantom Testing}

An anatomical phantom of a buttocks and pelvis was fabricated to enable experimental measurement of deep tissue pressures (Linder-Ganz et al., 2009). The anatomical phantom was made from Sylgard 184 silicone (Dow Corning; Midland, MI) which was poured into a plaster mold of human buttocks, lower back and legs. A polyurethane foam pelvis replica (Sawbones; Vashon Island, WA) was suspended within the mold in the correct anatomic location with a $3 \mathrm{~cm}$ gap between the ischial tuberosities and the surface of the mold as shown in Fig. 3 . The silicone was allowed to polymerize for four days. Sylgard 184 was chosen because of its similarities to soft tissue properties with an elastic modulus of $1.8 \mathrm{MPa}$ and Poisson's ratio of 0.45 (Palchesko et al., 2012). The pelvis was instrumented with three pressure manometers (Omega Engineering Inc., Norwalk, CT) on each ischial tuberosity and two on the sacrum to facilitate measurement of deep tissue pressures at these locations.

The phantom model was then placed on ten different interface support arrays as described in Table 2. The support arrays varied in geometry (cylindrical, spherical), size and spacing. Cylinders were arranged longitudinally across the seat at specified spacing and spheres were arranged in a regular square grid at the designated spacing. The anatomic phantom was placed on each support array and loaded in axial compression up to $490 \mathrm{~N}$ with a Mechanical Testing machine (MTS Systems Corporation; Eden Prairie, MN). While loaded, the pressure at each deep tissue location under the ischial tuberosities and sacrum was recorded. Axial load was then removed and the support array was modulated (shifted anteriorly) by a distance of one half of the support spacing so that regions of the phantom surface which were previously unsupported were in contact with a support and regions previously supported were relieved of contact. For each support array, the phantom was loaded and pressures were measured five times $(n=5)$ both before and after modulating the array. Differences in deep tissue pressure as a result of modulating the seat support array were measured using ANOVA and Tukey's post hoc test with values deemed statistically significant when $\alpha \leq 0.05$.

\section{Pressure Mapping}

Pressure mapping was utilized to measure seat interface pressures as volunteers sat on different interface support arrays. A high resolution pressure mat (Tekscan, South Boston MA) was used to measure interface pressures during sitting on the support arrays described in Table 2 and 3. Prototype support arrays were made by arranging cylinders (longitudinally or axially) or spheres of different diameters in specified patterns. Initially, the axial cylinders were spaced in rows and columns. Within each row, the cylinders were separated by $3.15 \mathrm{~mm}$ (between edges) and adjacent rows were spaced as described in Table 3. Pressure data were collected during five replicates $(n=5)$ of sitting for each support array. Array patterns which facilitated pressures of less than $32 \mathrm{mmHg}$ between supports were noted as potentially clinically viable.

Based on the results from the rectangular arrays, two additional "interrupted" array patterns were tested as shown in Fig. 4. These array patterns were designed to support a small circular or square region of tissue at its perimeter leaving it unsupported in the middle. When the array was modulated, the previously unsupported areas became supported and the previously supported areas became unsupported to allow the tissue to reperfuse.

Again, data were collected during five replicates $(n$ $=5$ ) of sitting for each support array. Array patterns which facilitated pressures of less than $32 \mathrm{mmHg}$ between supports were noted as potentially clinically viable. 


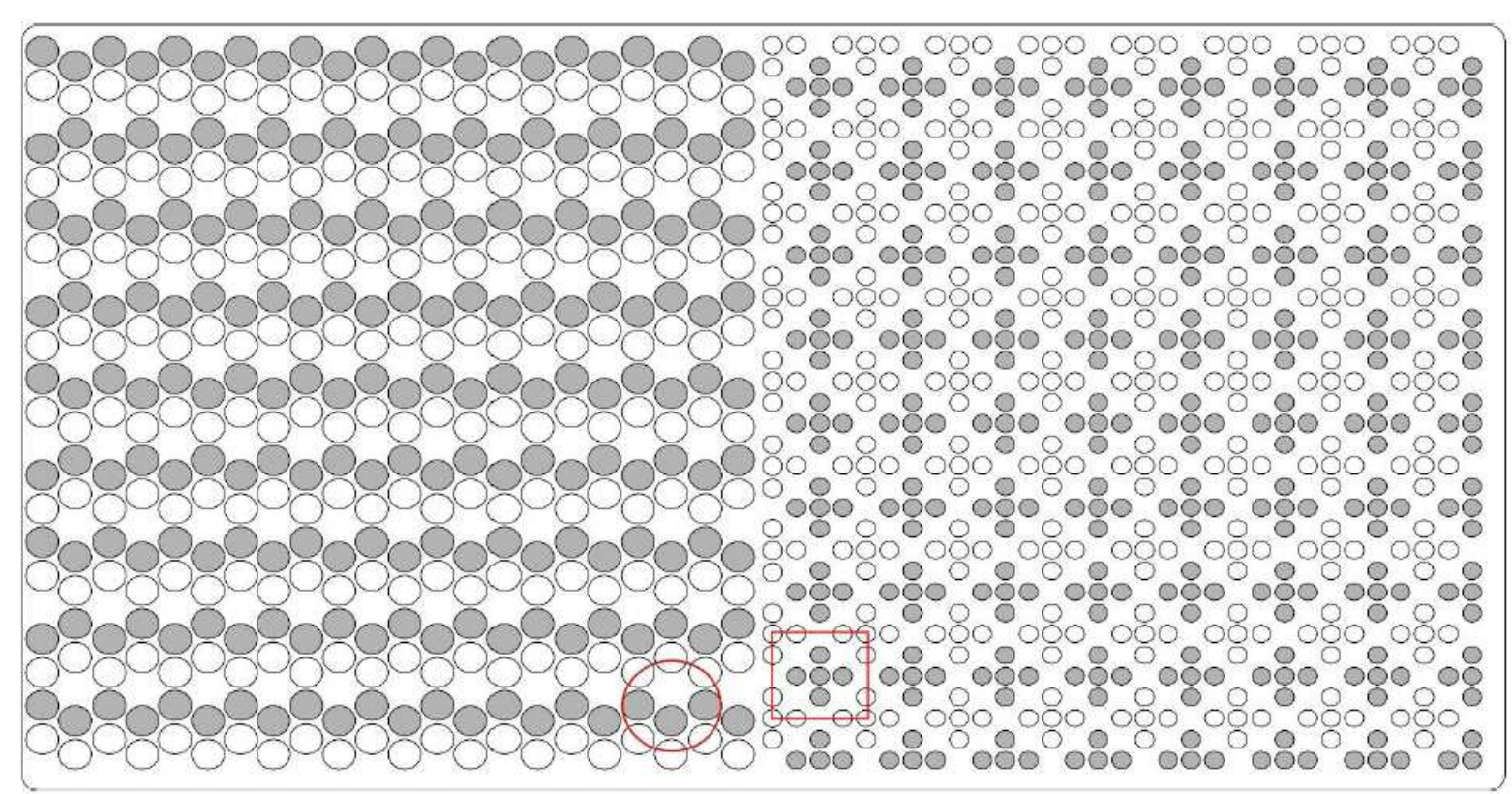

Fig. 4. The test arrays were constructed of dowels $6.35 \mathrm{~mm}$ in diameter arranged in an interrupted circle pattern (left) or interrupted box pattern (right). Dark cylinders provide support before modulating array and white cylinders provide support after modulating the array

Table 3. Interface support array sizes and spacings

\begin{tabular}{lc}
\hline $\begin{array}{l}\text { Support } \\
\text { diameter }(\mathrm{mm})\end{array}$ & $\begin{array}{l}\text { Support spacing } \\
\text { between rows }(\mathrm{mm})\end{array}$ \\
\hline 3.15 & 9.5 \\
3.15 & 19.0 \\
3.15 & 28.5 \\
3.15 & 38.0 \\
3.15 & 47.5 \\
6.35 & 12.7 \\
6.35 & 25.4 \\
6.35 & 38.1 \\
6.35 & 50.8 \\
6.35 & 63.5 \\
12.7 & 19.0 \\
12.7 & 38.0 \\
12.7 & 57.0 \\
12.7 & 76.0 \\
19 & 25.4 \\
19 & 50.8 \\
19 & 76.2 \\
\hline
\end{tabular}

\section{Results}

\section{Finite Element Analysis}

The finite element model provided a representation of soft tissue deformation on a flat surface and one support array as shown in Fig. 5. Results indicated that maximum superficial tissue pressures occurred over the individual supports of the support array and maximum deep tissue pressures occurred at the ischial tuberosity as shown in Fig. 6. The mean and peak deep tissue pressure beneath the ischial tuberosity was approximately 7.5 and
$22 \mathrm{mmHg}$, respectively. The mean pressure at the superficial tissue above the individual supports was approximately $12 \mathrm{mmHg}$ with a peak pressure of 15 $\mathrm{mmHg}$. The minimum pressure of superficial tissues located between the individual hemispherical supports was approximately $0.5 \mathrm{mmHg}$.

\section{Anatomical Phantom Testing}

Deep pressures measured during testing of each support array with the anatomical phantom are shown in Table 4. The magnitudes of pressure were consistently greatest at the center of the ischial tuberosities. When the axial load of $490 \mathrm{~N}$ was applied, the pressures increased by a mean $141.6 \mathrm{mmHg}$ in the deep tissues. When the phantom was placed on an array of $22 \mathrm{~mm}$ diameter longitudinally oriented cylindrical supports, modulating the array resulted in a mean decrease in all pressures of 6.4 and $19.9 \mathrm{mmHg}$ for supports spaced at $7.8 \mathrm{~mm}$ and $25.4 \mathrm{~mm}$ respectively. Similarly, when the phantom was placed on an array of $26 \mathrm{~mm}$ diameter longitudinally oriented cylindrical supports, modulating the array resulted in a mean decrease in all pressures of 13.5 and $24.4 \mathrm{mmHg}$ for supports spaced at 7.8 and $25.4 \mathrm{~mm}$, respectively. When placed on $34 \mathrm{~mm}$ diameter longitudinally oriented cylindrical supports, mean pressures decreased 9.5 and $13.8 \mathrm{mmHg}$ for supports spaced at 7.8 and $25.4 \mathrm{~mm}$, respectively. Using spherical supports, modulating the array resulted in a mean change in all pressures of 7.6, 19.5 and $18.4 \mathrm{mmHg}$ when the spacing between supports was $6.35,25.4$ and $51 \mathrm{~mm}$, respectively. 
The change in magnitude of deep pressures for each location measured is shown in Table 4 . While none of the support arrays tested with the anatomical phantom statistically significantly reduced pressure at all deep tissue locations, the trend was that pressures everywhere were reduced when the support array was modulated. The support arrays which most effectively reduced pressure when they were modulated were the $26 \mathrm{~mm}$ cylinders spaced at $25.4 \mathrm{~mm}$, the $16.2 \mathrm{~mm}$ diameter spheres spaced at $25.4 \mathrm{~mm}$ and the same spheres spaced at $51 \mathrm{~mm}$.

Table 4. Deep pressure change measured in the anatomical phantom

\begin{tabular}{|c|c|c|c|c|c|c|c|c|c|}
\hline Sensor location & $\begin{array}{l}22 \mathrm{~mm} \\
\text { cylinder } \\
7.8 \mathrm{~mm} \\
\text { spacing }\end{array}$ & $\begin{array}{l}22 \mathrm{~mm} \\
\text { cylinder } \\
25.4 \mathrm{~mm} \\
\text { spacing }\end{array}$ & $\begin{array}{l}26 \mathrm{~mm} \\
\text { cylinder } \\
7.8 \mathrm{~mm} \\
\text { spacing }\end{array}$ & $\begin{array}{l}26 \mathrm{~mm} \\
\text { cylinder } \\
25.4 \mathrm{~mm} \\
\text { spacing }\end{array}$ & $\begin{array}{l}34 \mathrm{~mm} \\
\text { cylinder } \\
7.8 \mathrm{~mm} \\
\text { spacing }\end{array}$ & $\begin{array}{l}34 \mathrm{~mm} \\
\text { cylinder } \\
25.4 \mathrm{~mm} \\
\text { spacing }\end{array}$ & $\begin{array}{l}16.2 \mathrm{~mm} \\
\text { sphere } \\
6.2 \mathrm{~mm} \\
\text { spacing }\end{array}$ & $\begin{array}{l}16.2 \mathrm{~mm} \\
\text { sphere } \\
25.4 \mathrm{~mm} \\
\text { spacing }\end{array}$ & $\begin{array}{l}16.2 \mathrm{~mm} \\
\text { sphere } \\
51 \mathrm{~mm} \\
\text { spacing }\end{array}$ \\
\hline Posterior left IT $^{\mathrm{b}}$ & $13.4^{* \mathrm{a}}$ & $-25.8 *$ & -2.1 & $-31.2 *$ & 7.2 & 11.3 & -6.2 & $-48.6^{*}$ & $-48.6^{*}$ \\
\hline Central left IT & -4.1 & $27.9 *$ & $-21.7 *$ & $39.8^{*}$ & $19.6^{*}$ & $51.7 *$ & $-14.4 *$ & $31.0 *$ & $16.5^{*}$ \\
\hline Anterior left IT & 0.0 & -7.2 & 1.0 & $21.5^{*}$ & -5.1 & -8.3 & $15.5^{*}$ & $-48.6^{*}$ & -7.2 \\
\hline Anterior right IT & -4.1 & 0.42 & 0.0 & $-44.3 *$ & $-15.5^{*}$ & 6.2 & 0.0 & -2.1 & -4.1 \\
\hline Central right IT & $-21.7 *$ & 6.2 & $-41.3 *$ & $-8.9 *$ & $-20.7 *$ & -1.0 & 3.1 & $-15.5^{*}$ & $32.1 *$ \\
\hline Posterior right IT & -5.17 & $-47.5^{*}$ & $34.1^{*}$ & -23.1 & 4.1 & $-15.5^{*}$ & 2.1 & $34.1 *$ & $-17.5^{*}$ \\
\hline Left coccyx & 4.1 & 35.1 & $7.3^{*}$ & -12.4 & -2.6 & 7.2 & -9.3 & -1.0 & -2.1 \\
\hline Right coccyx & 3.1 & -1.0 & -1.0 & $-14.0 *$ & -2.7 & -9.3 & -10.3 & $15.5^{*}$ & $18.6^{*}$ \\
\hline
\end{tabular}

a. ${ }^{*}$ Denotes reductions in pressure which are statistically significant $(\mathrm{p}<0.05)$

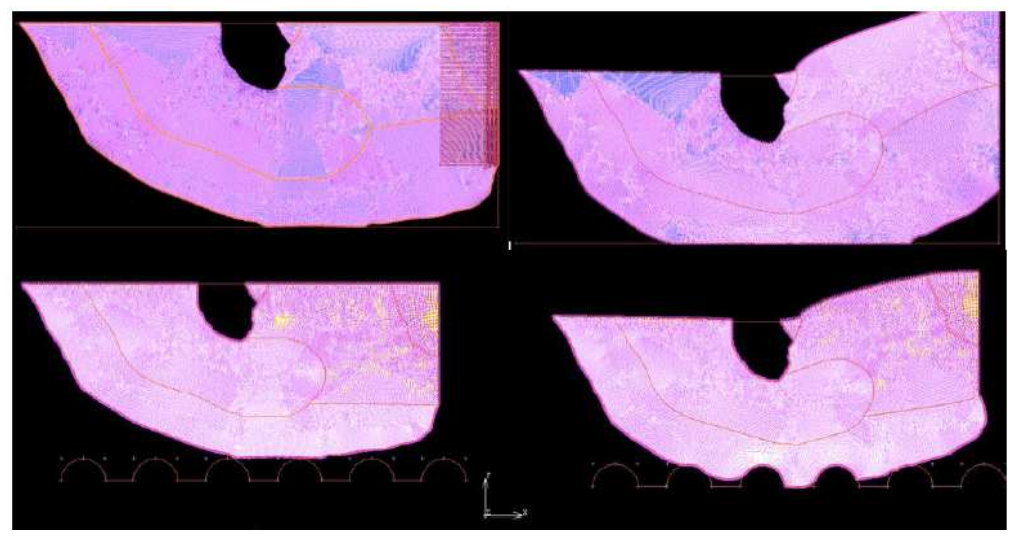

Fig. 5. The finite element model before (left) and after (right) ischial tuberosity displacement indicates how the soft tissues deform on a flat surface (top) and spherical support array (bottom)
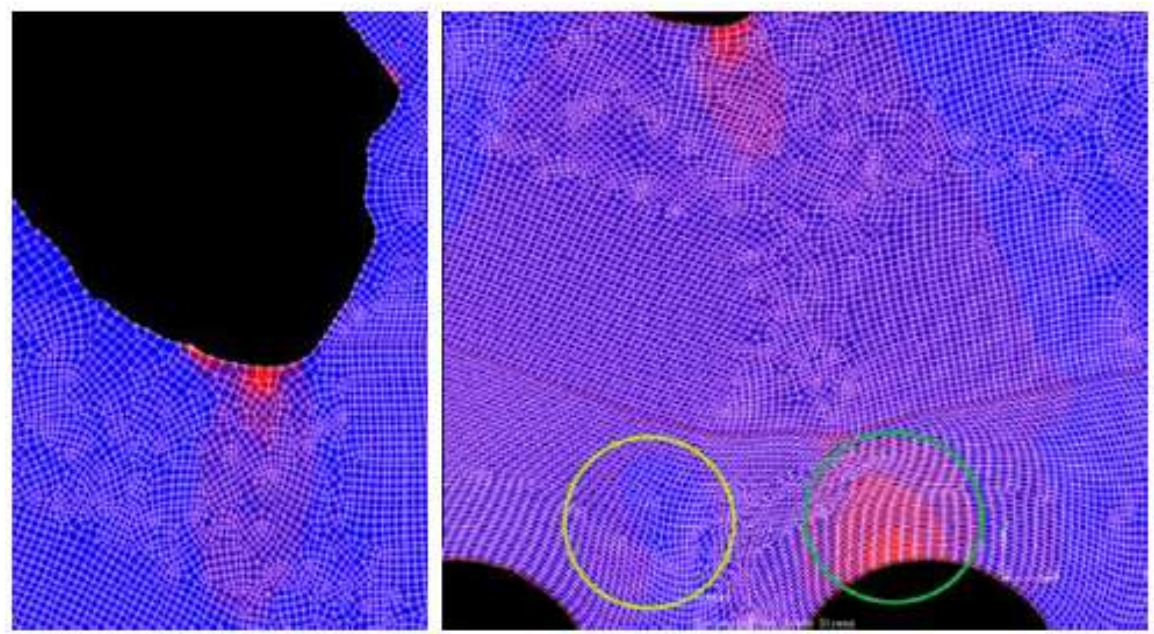

Fig. 6. A close up of the soft tissue adjacent to the ischial tuberosity (left) shows regions of peak pressure (red elements). A close up of the soft tissue over the hemispherical support (right) shows a region of maximum superficial tissue pressure (green circle) and minimum superficial tissue pressure (yellow circle) between supports 

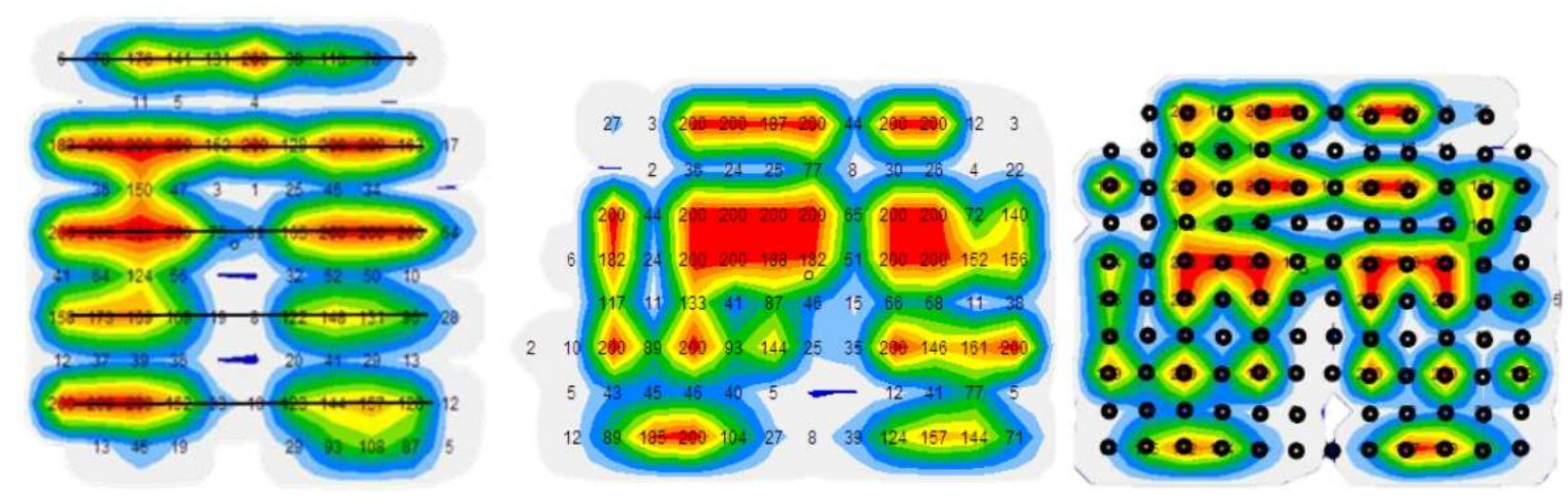

Fig. 7. Pressure maps of sitting on an array of longitudinally oriented cylinders (left), spheres (middle) and a regularly spaced array of axially oriented cylinders (right) indicated that tissue pressure is not localized to the area contacting the supports (indicated with black lines and circles) but also demonstrated hammocking. Colored areas show pressures which exceed $32 \mathrm{mmHg}$

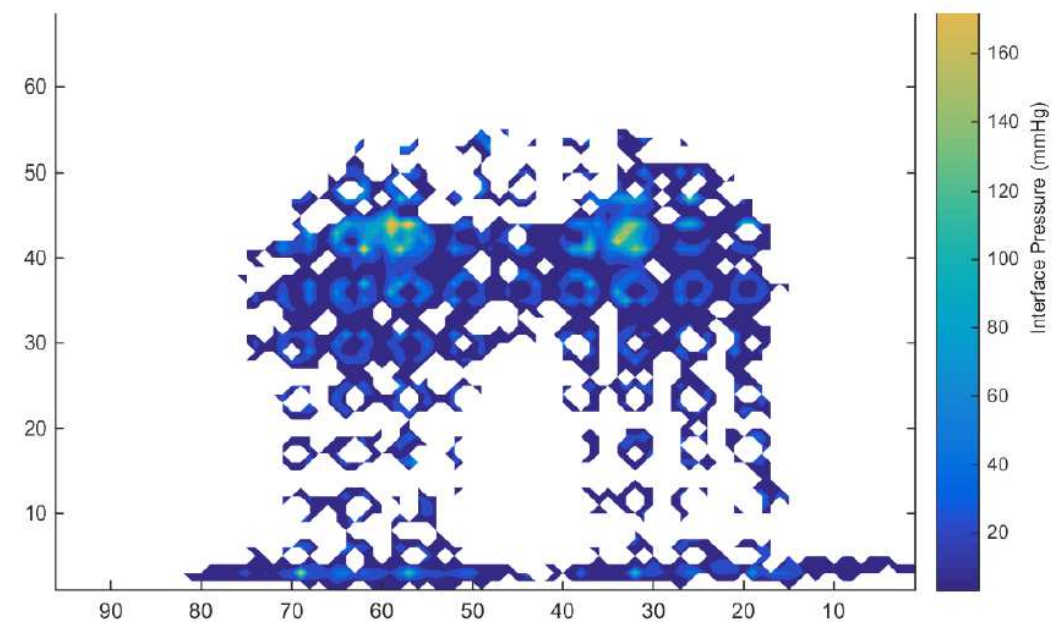

Fig. 8. High resolution pressure maps show that for the interrupted arrays pressure is localized to the perimeter of the support array, but in the unsupported regions the pressures are below $32 \mathrm{mmHg}$

\section{Pressure Mapping}

Pressure mapping provided a quantitative twodimensional representation of pressure magnitude at the interface between the buttocks and support array. For each support array configuration tested, peak pressures were always located at the ischial tuberosities. As expected, pressures were highest at the location where the supports contacted the user and were lowest in the unsupported regions (the gaps between supports). The magnitude of pressure in the unsupported locations was analyzed to determine if pressures were below $32 \mathrm{mmHg}$ - the magnitude at which reperfusion is likely to occur. In all regularly spaced arrays (rows and columns) of longitudinal cylinders, axial cylinders and spheres, there was hammocking, or high pressure between supports. In all cases of regular spaced arrays the pressure in the unsupported regions (between the supports) exceeded 32 $\mathrm{mmHg}$ in several locations (Fig. 7), indicating that the support array would not allow reperfusion of the tissues in those regions. This was particularly prominent near the ischial tuberosities. Based on these initial results, we tested additional array configurations which included interrupted support patterns of axially oriented cylinders (Fig. 4). The interrupted support patterns enclose regions of tissue within their perimeter. Results from the interrupted arrays demonstrated that pressure is localized to the perimeter of the support array (the perimeter of the circles or squares), but in the unsupported regions (the area within the circle or square) the pressures are substantially lower and in most cases are below 32 mmHg everywhere, as shown in Fig. 8.

\section{Discussion}

In spite of decades of awareness of the pathomechanisms underlying pressure ulcer formation, the incidence continues to rise worldwide. The cost of 
treatment has also increased substantially and is a sizeable burden on healthcare systems. New prevention recommendations include educating caregivers, enhancing nutrition and using dynamic support surfaces as interfaces (Qaseem et al., 2015). The use of dynamic support surfaces purports to cause a reduction in pressure ulcer formation in high risk patients (Inma et al., 1993). However, the effectiveness of existing dynamic support surfaces in reducing incidence of pressure ulcers remains controversial (Reddy et al., 2006; McInnes et al., 2011; Qaseem et al., 2015).

There are additional challenges for wheelchair users. Current dynamic support surfaces employ electric pumps which alternate air or water pressures in a pad or fluidized bed. These are generally expensive, large and costly to operate (Lyder, 2003; Reddy et al., 2006; McInnes et al., 2011). Ideally, dynamic support systems modulate at 10-20 min intervals to allow reperfusion of tissues (Stockton and Rithalia, 2007). Existing dynamic support systems are hard to make transportable, difficult to adjust and difficult to maintain.

For wheelchair users who are able, self-repositioning every 15-30 min can be an effective means of preventing ischemia and pressure ulcer formation (Stockton et al., 2009). However, compliance is low and so alternative preventive measures are needed (Van Den Bos et al., 2011; White et al., 1989). One potential shortcoming of existing dynamic support surfaces is that they are based on regular arrays of supports (i.e., rows and columns). Results from this study demonstrate that modulating pressure in an array of supports that are equally spaced is not effective in reducing pressure below $32 \mathrm{mmHg}$. Hammocking of tissues between supports results in high pressures even in areas that are unsupported.

In our parametric approach to testing various array configurations and support geometries, only the interrupted array of axially oriented cylinders eliminated the effects of hammocking. Whether longitudinally oriented cylinders, axial oriented cylinders, or spherical supports, neither the deep pressures nor the surface pressures were substantially reduced when the array was comprised of a regular pattern of supports.

Based on our pressure mapping, the interrupted arrays of circles, squares and rectangles resulted in pressure reduction below $32 \mathrm{mmHg}$ when the support array was modulated. Tissue supported by the array demonstrated pressures in excess of $32 \mathrm{mmHg}$ while those unsupported had pressures below $32 \mathrm{mmHg}$. These data suggest that dynamic surface supports can be optimized based on the geometry and size of the individual supports and the pattern of the array to further reduce the likelihood of pressure ulcer formation. The simple pattern of supports is also conducive to mechanical actuation and the small size and weight needed for a wheelchair interface. Further research should target additional optimization of the array and demonstrate efficacy for reducing deep and superficial pressures.

\section{Funding Information}

This work was supported by a grant from the endowment of the Center for Disability Services, Albany, New York. The authors would like to acknowledge additional support from Global Engineering Teams, Berlin, Germany.

\section{Author's Contributions}

Joshua Peterson contributed: Experimental designs, prototype fabrication, data collection, analysis and manuscript preparation. Colleen P. Healey was responsible for: experimental design, data collection, analysis. Jacobus Visser contributed: Computational analysis, prototype fabrication, data analysis. Cameron Crombie was responsible for: Computational analysis, data analysis. Eric H. Ledet was the principal investigator and responsible for: Study design, data analysis, manuscript preparation.

\section{Ethics}

The authors have nothing to disclose.

\section{References}

Brienza, D.M., P.E. Karg, M.J. Geyer, S. Kelsey and E. Trefler, 2001. The relationship between pressure ulcer incidence and buttock-seat cushion interface pressure in at-risk elderly wheelchair users. Arch. Phys. Med. Rehabilitat., 82: 529-533.

DOI: $10.1053 /$ apmr.2001.21854

Coleman, S., C. Gorecki, E.A. Nelson, S.J. Closs and T. Defloor et al., 2013. Patient risk factors for pressure ulcer development: Systematic review. Int. J. Nurs. Stud., 50: 974-1003.

DOI: 10.1016/j.ijnurstu.2012.11.019

Conine, T.A., D. Daechsel and C. Hershler, 1993. Pressure sore prophylaxis in elderly patients using slab foam or customized contoured foam wheelchair cushions. Occupat. Therapy J. Res., 13: 101-116. DOI: $10.1177 / 153944929301300203$

Cuddigan, J., D.R. Berlowitz and E.A. Ayello, 2001. Pressure ulcers in America: Prevalence, incidence and implications for the future. Adv. Skin Wound Care, 14: 208-215. PMID: 11902346

Dinsdale, S., 1974. Decubitus ulcers: Role of pressure and friction in causation. Arch. Phys. Med. Rehabilitat., 55: 147-152. PMID: 4595834

Grey, J.E., K.G. Harding and S. Enoch, 1974. ABC of wound healing: Pressure ulcers. Brit. Med. J., 332: 472-472. DOI: $10.1136 / \mathrm{bmj} .332 .7539 .472$ 
Hollington, J., S.J. Hillman, C. Torres-Sánchez, J. Boeckx and N. Crossan, 2014. ISO 16840-2:2007 load deflection and hysteresis measurements for a sample of wheelchair seating cushions. Med. Eng. Phys., 36: 509-515.

DOI: $10.1016 /$ j.medengphy.2013.10.010

Inma, K.J., W.J. Sibbald, F.S. Rutledge and B.J. Clark, 1993. Clinical utility and cost-effectiveness of an air suspension bed in the prevention of pressure ulcers. J. Am. Med. Assoc., 269: 1139-1143.

DOI: $10.1001 /$ jama.269.9.1139

Khor, H.M., J. Tan, N.I. Saedon, S.B. Kamaruzzaman and A.V. Chin et al., 2014. Determinants of mortality among older adults with pressure ulcers. Arch. Gerontol. Geriatr., 59: 536-541. DOI: 10.1016/j.archger.2014.07.011

Kosiak, M., 1959. Etiology and pathology of ischemic ulcers. Arch. Phys. Med. Rehabilitat., 40: 62-69. PMID: 13618101

Krouskop, T.A., N.P. Reddy, W.A. Spencer and J.W. Secor, 1978. Mechanisms of decubitus ulcer formation-an hypothesis. Med. Hypotheses, 4: 37-39. DOI: 10.1016/0306-9877(78)90025-7

Linder-Ganz, E., G. Yarnitzky, Z. Yizhar, I. Siev-Ner and A. Gefen, 2009. Real-time finite element monitoring of sub-dermal tissue stresses in individuals with spinal cord injury: Toward prevention of pressure ulcers. Annals Biomed. Eng., 37: 387-400. DOI: 10.1007/s10439-008-9607-8

Lyder, C.H., 2003. Pressure ulcer prevention and management. J. Am. Med. Associat., 289: 223-226. DOI: 10.1001/jama.289.2.223

McInnes, E., A. Jammali-Blasi, S.E.M. Bell-Syer, J.C. Bumville and N. Cullum. 2011. Support surfaces for pressure ulcer prevention. The Cochrane Library.

Ogden, R., 1972. Large deformation isotropic elasticityon the correlation of theory and experiment for incompressible rubberlike solids. Proceedings of the Royal Society of London A: Mathematical, Physical and Engineering Sciences, (PES' 72), The Royal Society, pp: 565-584.

Oomens, C.W.J, O.F.J.T. Bressers, E.M.H. Bosboom, C.V.C. Bouten and D.L. Bader, 2003. Can loaded interface characteristics influence strain distributions in muscle adjacent to bony prominences? Comput. Meth. Biomechan. Biomed. Eng., 6: 171-180. DOI: 10.1080/1025584031000121034

Palchesko, R.N., L. Zhang, Y. Sun and A.W. Feinberg, 2012. Development of polydimethylsiloxane substrates with tunable elastic modulus to study cell mechanobiology in muscle and nerve. Public Library Sci. One, 7: e51499-e51499. DOI: 10.1371/journal.pone.0051499
Palfreyman, S.J. and P.W. Stone, 2015. A systematic review of economic evaluations assessing interventions aimed at preventing or treating pressure ulcers. Int. J. Nurs. Stud., 52: 769-788. DOI: 10.1016/j.ijnurstu.2014.06.004

Qaseem, A., L.L. Humphrey, M.A Forciea, M. Starkey and T.D. Denberg, 2015. Treatment of pressure ulcers: A clinical practice guideline from the American College of Physicians. Annals Internal Med., 162: 370-9. DOI: 10.7326/m14-1568

Reddy, M., S.S. Gill and P.A. Rochon, 2006. Preventing pressure ulcers: a systematic review. J. Am. Med. Assoc., 296: 974-984. DOI: 10.1001/jama.296.8.974

Redelings, M.D., N.E. Lee and F. Sorvillo, 2005. Pressure ulcers: More lethal than we thought? Adv. Skin Wound Care, 18: 367-372. DOI: 10.1097/00129334-200509000-00010

Reichel, S.M., 1958. Shearing force as a factor in decubitus ulcers in paraplegics. J. Am. Med. Assoc., 166: $762-763$. DOI: $10.1001 /$ jama.1958.62990070004010a

Reuler, J.B. and T.G. Cooney, 1981. The pressure sore: Pathophysiology and principles of management. Annals Internal Med., 94: 661-666. DOI: 10.7326/0003-4819-94-5-661

Richardson, R.R. and P.R. Meyer, 1981. Prevalence and incidence of pressure sores in acute spinal cord injuries. Spinal Cord, 19: 235-247. DOI: $10.1038 /$ sc. 1981.47

Sacks, A.H., 1989. Theoretical prediction of a time-atpressure curve for avoiding pressure sores. J. Rehabilitat. Res. Dev., 26: 27-34.

Sen, C.K., G.M. Gordillo, S. Roy, R. Kirsner and L. Lambert et al., 2009. Human skin wounds: A major and snowballing threat to public health and the economy. Wound Repair Regenerat., 17: 763-771. DOI: $10.1111 /$ j.1524-475x.2009.00543.x

Sopher, R., J. Nixon, C. Gorecki and A. Gefen, 2010. Exposure to internal muscle tissue loads under the ischial tuberosities during sitting is elevated at abnormally high or low body mass indices. J. Biomechan., 43: 280-286. DOI: 10.1016/j.jbiomech.2009.08.021

Stekelenburg, A., 2005. Mechanisms associated with deep tissue injury induced by sustained compressive loadinged. Eindhoven, The Netherlands: Universiteitsdrukkerij TU Eindhoven.

Stockton, L., K.S. Gebhardt and M. Clark, 2009. Seating and pressure ulcers: Clinical practice guideline. J. Tissue Viability, 18: 98-108. DOI: $10.1016 /$ j.jtv.2009.09.001

Stockton, L. and S. Rithalia, 2007. Is dynamic seating a modality worth considering in the prevention of pressure ulcers? J. Tissue Viability, 17: 15-21. DOI: $10.1016 /$ j.jtv.2007.09.011 
Stockton, L. and S. Rithalia, 2009. Pressure-reducing cusions: Perceptions of comfort from the wheelchair users' perspective using interface pressure, temperature and humidity measurements. J. Tissue Viability, 18: 28-35. DOI: 10.1016/j.jtv.2007.09.006

Sullivan, N. and K.M. Schoelles, 2013. Preventing infacility pressure ulcers as a patient safety strategy: A systematic review. Annals Internal Med., 158: 410-416.

DOI: 10.7326/0003-4819-158-5-201303051-00008

Taylor, S.J., 2003. An overview of evaluation for wheelchair seating for people who have had strokes. Top. Stroke Rehabilitat.

DOI: 10.1310/p145-wvvy-b2j3-kxgb

Van Den Bos, J., K. Rustagi, T. Gray, M. Halford and E. Ziemkiewicz et al., 2011. The $\$ 17.1$ billion problem: The annual cost of measurable medical errors. Health Affairs, 30: 596-603.

DOI: $10.1377 /$ hlthaff.2011.0084
White, G.W., R.M. Mathews and S.B. Fawcett, 1989. Reducing risk of pressure sores: Effects of watch prompts and alarm avoidance on wheelchair pushups. J. Applied Behav. Anal., 22: 287-295. DOI:10.1901/jaba.1989.22-287

WHO, 2008. World Alliance for Patient Safety. Summary of the evidence on patient safety: Implications for research. The Research Priority Setting Working Group of the World Alliance for Patient Safety. World Health Organization, Geneva.

Xakellis, G., 1992. Guidelines for the prediction and prevention of pressure ulcers. The Agency for Health Care Policy and Research. J. Am. Board Family Pract., 6: 269-278. DOI: 10.1111/j.15325415.1995.tb06095.x 